\title{
Right Ventricular Myocardial Responses to Chronic Pulmonary Regurgitation in Lambs: Disturbances of Activation and Conduction
}

\author{
ROSAIRE GRAY, GOTTFRIED GREVE, RUOLI CHEN, CHRISTOPHER FRY, DAVID BARRON, \\ MAX J. LAB, PAUL A. WHITE, ANDREW N. REDINGTON, AND DANIEL J. PENNY \\ Institute of Urology and Nephrology, University College, London W1W 7EY [R.G., C.F.], The Institute of \\ Child Health, University College, London WC1N 1EH [G.G., D.B., P.A.W., A.N.R., D.J.P.], University \\ College London, and National Heart and Lung Institute, London SW3 6LY [R.C., M.J.L.], U.K., and \\ Department of Cardiology, The Royal Children's Hospital and University of Melbourne, Australia 3052
} [D.J.P.]

\section{ABSTRACT}

Patients after repair of tetralogy of Fallot are at increased risk of arrhythmic death. Clinical data suggest that pulmonary regurgitation predisposes to these arrhythmias, although the cellular electrophysiologic effects of pulmonary regurgitation are unknown. We induced pulmonary regurgitation in lambs, and 3 mo later, having quantified the pulmonary regurgitant (PR) fraction, studied right ventricular mechanical and electrophysiologic properties in vivo and in vitro. The PR fraction was greater in PR (75 $\pm 10 \%)$ than in sham-operated animals $(8 \pm 4 \% ; p<0.01)$. In vivo, monophasic action potential duration and activation time, at rest and during acute right ventricular stretch, were similar in both groups. However, the dispersion of activation time was greater in PR animals at rest $(13 \pm 1.1$ versus $8 \pm 1.1 \mathrm{~ms} ; p<$ $0.05)$. Furthermore, the dispersion of activation increased during right ventricular stretch in PR, but not in sham-operated animals. In vitro, myocardial force-frequency responses were similar in both groups, indicating preserved systolic performance, but mechanical restitution studies showed a prolonged refractory period $(447 \pm 22$ versus $370 \pm 26 \mathrm{~ms} ; p<0.05)$ and a decreased recovery time constant $(184 \pm 19$ versus $265 \pm 20 \mathrm{~ms} ; p<$ $0.001)$ in PR animals, indicating altered calcium cycling. Fur- thermore, the myocardial conduction velocity was reduced in PR animals $(31 \pm 3.58$ versus $47.9 \pm 5.1 \mathrm{~cm} / \mathrm{s} ; p<0.01)$, resulting from a 2-fold increase in intracellular resistance (437.25 \pm 125.93 versus $194 \pm 43.27 \Omega \cdot \mathrm{cm} ; p=0.025)$. Chronic PR leads to inhomogeneity of right ventricular activation, alters myocardial calcium cycling, reduces conduction velocity, and increases intracellular resistivity. These may contribute to the development of arrhythmias associated with PR, including those in patients after tetralogy repair. (Pediatr Res 54: 529-535, 2003)

\section{Abbreviations}

MEF, mechanoelectric feedback

PR, pulmonary regurgitation

$\mathbf{R V}$, right ventricular

$\mathbf{L V}$, left ventricular

SO, sham operated

MAP, monophasic action potential

AT, activation time

AP, action potential

APD, action potential duration
Advances in surgery have significantly improved the shortterm prognosis for patients with congenital heart disease. Nonetheless, at medium-term follow-up, arrhythmic death remains an important problem, with patients after repair of tetralogy of Fallot being at particular risk $(1,2)$.

We and others have emphasized the contribution of abnormal RV mechanics to arrhythmia in patients after repair of

Received August 14, 2002; accepted January 23, 2003.

Correspondence: D.J. Penny, M.D., Cardiology Department, Royal Children's Hospital, Flemington Road, Melbourne, Australia 3052; e-mail: dan.penny@rch.org.au

Funded by The British Heart Foundation. G.G. was supported by The Norwegian Research Council.

DOI: 10.1203/01.PDR.0000084829.67270.FA tetralogy of Fallot (3-5). We postulated that postoperative PR provides the substrate for arrhythmia by altering the electrophysiologic properties of the RV, a phenomenon termed MEF $(6,7)$. Despite increasing clinical data, this hypothesis is lacking in a number of key respects. First, although there are numerous studies of the effects of acute changes in ventricular loading on myocardial electrophysiology, there are few clinically relevant models of chronic alterations in load that investigate these phenomena. Second, it is unknown whether the processes that underlie LV MEF also pertain to the RV, which differs from the left with regard not only to shape and mechanics $(8,9)$ but also to its responses during changes in load $(10$, 11). Finally, although a variety of mechanisms appear to 
contribute to LV MEF, including activation of stretch-activated channels and changes in intramyocardial conduction (12), the precise electrophysiologic mechanisms through which MEF may occur during PR remain undefined.

The aim of this study was to investigate the in vivo and in vitro electrophysiologic properties of the RV in a model of chronic PR.

\section{METHODS}

All experiments were performed according to the Guidance on the Operation of the Animals (Scientific Procedures) Act 1986, under license from the UK Home Office.

Surgical preparation. We anesthetized 12 lambs aged 6-12 wk with intramuscular ketamine, $5 \mathrm{mg} / \mathrm{kg}$, and xylazine, 0.1 $\mathrm{mg} / \mathrm{kg}$, then administered an i.v. bolus of propofol, $2 \mathrm{mg} / \mathrm{kg}$. We intubated and ventilated them with $\mathrm{O}_{2} / \mathrm{N}_{2} \mathrm{O}$ and halothane (1-1.5\%), and through a median sternotomy, encircled the caval veins and the main pulmonary artery with snares. In six, we tightened the snares, made a $2-\mathrm{cm}$ arteriotomy in the main pulmonary artery, and excised two leaflets of the pulmonary valve. In the other six (SO), we tightened the snares for $2 \mathrm{~min}$. The chest was closed, and the animal was allowed to recover.

In vivo physiologic study. Three months later we anesthetized, intubated, and ventilated the lambs as before, performed a median sternotomy, and encircled the main pulmonary artery with a snare. Through a pursestring suture in the RV outflow tract we passed a $4 \mathrm{~F}$ integrated conductance and micromanometer-tipped catheter (Millar Instruments, Houston, TX, U.S.A.) for measurement of ventricular pressure and volume (13) and placed tripods, mounted with suction electrodes, for MAP recording over the apex, outflow, and inflow regions of the RV. Although minimal differences in the distance between the tripods may have occurred because of variation in the distribution of the coronary arterial branches, every effort was made to ensure that the distance between tripods was similar in all animals. We monitored hemodynamic variables for at least 15 min to ensure stability and then calibrated the conductance catheter system (14). We recorded RV pressure and volume as well as MAPs during steady state to measure PR fraction (15) and MAP duration and then, to assess the RV responses to stretch, repeated these recordings during complete occlusion of the main pulmonary artery.

The output from the integrated catheter was fed into a signal-processing unit (Sigma-5-DF; Cardiodynamics, Zoetermeer, The Netherlands). RV volume was derived and displayed with RV pressure $(14,15)$. The amount of PR was measured from the ventricular pressure-volume loops according to described methods and indexed to stroke volume to derive a PR fraction (15). The outputs from the limb electrodes and the MAP tripods were amplified (Lectromed MT8, Hertfordshire, UK) and digitized at $1000 \mathrm{~Hz}$ with an analog-to-digital converter (model 1401; Cambridge Electronic Design, Cambridge, U.K.). Data were stored with a digital acquisition program (Spike 2; Cambridge Electronic Design) and analyzed with customized software. We defined the interval from the onset of the QRS complex on the ECG to the onset of the upstroke of the earliest MAP as AT. To examine regional nonuniformity of depolarization, we derived the dispersion of AT from the maximum difference for this measure recorded for the three tripods. We measured MAP duration from the onset of the upstroke of the MAP to $25 \%\left(\mathrm{MAPD}_{25}\right)$ and $70 \%\left(\mathrm{MAPD}_{70}\right)$ repolarization. We classified arrhythmias according to the guidelines of the Lambeth Convention (16).

In vitro studies. After sacrificing the animal with intraaortic sodium pentobarbitone, we rapidly excised the heart and mounted RV trabeculae in a superfusion trough, tied at one end to a fixed hook and at the other end to an isometric force transducer using $100-\mu \mathrm{m}$ silk thread. Segments of muscle with diameters $<1 \mathrm{~mm}$ and lengths of $3-5 \mathrm{~mm}$, measured using a binocular microscope with a calibrated eyepiece graticule under $\times 30$ magnification, were superfused with Tyrode's solution containing (in $\mathrm{mM}$ ) NaCl, $118 ; \mathrm{KCl}, 4.0 ; \mathrm{NaHCO}_{3}, 24$; $\mathrm{NaH}_{2} \mathrm{PO}_{4}, 0.4 ; \mathrm{MgCl}_{2}, 1.8$; glucose, 6.1 ; sodium pyruvate, 5.0. The solution was gassed with a mixture containing $95 \% \mathrm{O}_{2} / 5 \%$ $\mathrm{CO}_{2}, \mathrm{pH} 7.35 \pm 0.03$, at $36 \pm 0.5^{\circ} \mathrm{C}$.

We measured peak isometric twitch tension during increasing stimulation frequencies $(0.1$ to $2.0 \mathrm{~Hz})$ and constructed force-frequency curves by expressing the tension generated at each stimulation frequency to that developed at a frequency of $0.1 \mathrm{~Hz}$. We measured mechanical restitution by interposing additional stimuli between regular stimuli at a basal frequency of $0.8 \mathrm{~Hz}$ and quantified the time course of force restoration by fitting the data to the relationship as follows:

$$
T=T_{\max } \times\left\{1-\exp \left[-\left(t-t_{0}\right) / \tau\right]\right\}
$$

where $T$ is tension, $T_{\max }$ is a constant, $\tau$ is the restitution time constant; $t$ is the ectopic beat interval, and $t_{0}$ the time when the curve intercepts the $y$ axis at $0 ; t_{0}$ is equivalent to the mechanical refractory period.

We made intracellular recordings of field-stimulated AP with $10 \mathrm{M} \Omega, 3 \mathrm{M} \mathrm{KCl}$-filled microelectrodes with reference to a streaming $\mathrm{KCl}$ bridge. APD was the time from the upstroke to $95 \%$ repolarization $\left(\mathrm{APD}_{95}\right)$ at increasing stimulation frequencies $(0.1$ to $2.0 \mathrm{~Hz})$.

We measured conduction velocity $(\theta=d / t)$ by stimulating the muscle at one end with insulated $\mathrm{Ag}-\mathrm{AgCl}$ electrodes on the muscle surface, using threshold pulses to minimize extracellular current spread. We recorded APs with a $\mathrm{KCl}$ electrode at known distances from these point-stimulating electrodes, measured with a graticule in the lens of a $\times 3$ binocular microscope. Conduction delay was the interval between the start of the stimulus artifact and the maximum AP upstroke velocity, $V_{\max }$. We calculated the time constant of the AP foot, $\tau_{a p}$, from a semilogarithmic plot of the initial $10 \mathrm{mV}$ depolarization of the conducted AP.

We derived intracellular resistivity $\left(R_{i}\right)$ from conduction velocity, $\theta$, and the time constant of the APD, $\tau_{\text {ap }}$, by rearranging the cable equation $(17,18)$ :

$$
\theta^{2}=a / 2 R_{i} \times C_{m} \times \tau_{a p}
$$

where $a$ is cell radius, and $C_{m}$, the specific membrane capacitance. We assumed $C_{m}$ to be a constant value of $1 \mu \mathrm{F} / \mathrm{cm}^{2}$ (18) and $a$ to be similar in the two groups. 


\section{RESULTS}

Pulmonary regurgitant fraction. RV pressure-volume recordings demonstrated an increase in volume during the pressure decline, indicating PR. The PR fraction was greater $(75 \pm$ $10 \%)$ in PR than in SO animals $(8 \pm 4 \% ; p<0.01)$.

$\boldsymbol{M A P}$ in vivo. Heart rate, $M A P D_{25}$ and $M A P D_{70}$ repolarization, and the interval from $\mathrm{MAPD}_{25}$ to $\mathrm{MAPD}_{70}$ were similar in both groups. Although RV AT was similar in both $\mathrm{SO}(11 \pm$ $1.5 \mathrm{~ms})$ and PR $(12 \pm 2.4 \mathrm{~ms})$ animals, AT dispersion was increased in the latter $(9.3 \pm 2.2$ versus $7.5 \pm 1.1 \mathrm{~ms} ; p<$ $0.05)$. Pulmonary arterial occlusion shortened $\mathrm{MAPD}_{25}$ by 28 \pm 6 and $22 \pm 4 \mathrm{~ms}$ in the $\mathrm{SO}$ and PR groups, and increased the interval from $\mathrm{MAPD}_{25}$ to $\mathrm{MAPD}_{70}$ by $14 \pm 5$ and $12 \pm 4 \mathrm{~ms}$, with no significant difference between groups (Fig. 1). Although AT was unaltered by occlusion, the dispersion of AT was increased to $13.6 \pm 2.4 \mathrm{~ms}$ in the PR group $(p<0.05)$, but not in the SO animals (Fig. 2).

Stretch-induced arrhythmias. Stretch-induced arrhythmias occurred during pulmonary arterial occlusion in both groups. Most were single premature beats, although in some of the PR animals, bigemini or short runs of ventricular tachycardia were observed. The proportion of stretch-induced arrhythmia was significantly greater in the PR animals (11 of 14 stretches versus seven of 18 stretches; $p<0.05$ ).

$\boldsymbol{R} \boldsymbol{V}$ weight. $\mathrm{RV}$ weight, normalized to body weight tended to be greater in the PR animals $(1.54 \pm 0.18$ versus $0.83 \pm 0.3$ $\mathrm{g} / \mathrm{kg} ; p<0.1)$, and the $\mathrm{RV}: \mathrm{LV}$ mass ratio was higher in this group $(1.1 \pm 0.2$ versus $0.7 \pm 0.1 ; p<0.05)$.

Mechanical properties of the $R$ V myocardium in vitro. $R V$ myocardium from all animals showed a positive forcefrequency relationship, with similar curves in each group (Fig. $3)$. Thus the ratios between tension generated at 1.0 and $0.1 \mathrm{~Hz}$ $\left(T_{1.0 / 0.1}\right)$ were similar in the PR $(1.83 \pm 0.23)$ and the SO $(2.15$ $\pm 0.21)$ animals. Mechanical restitution studies in myocardium
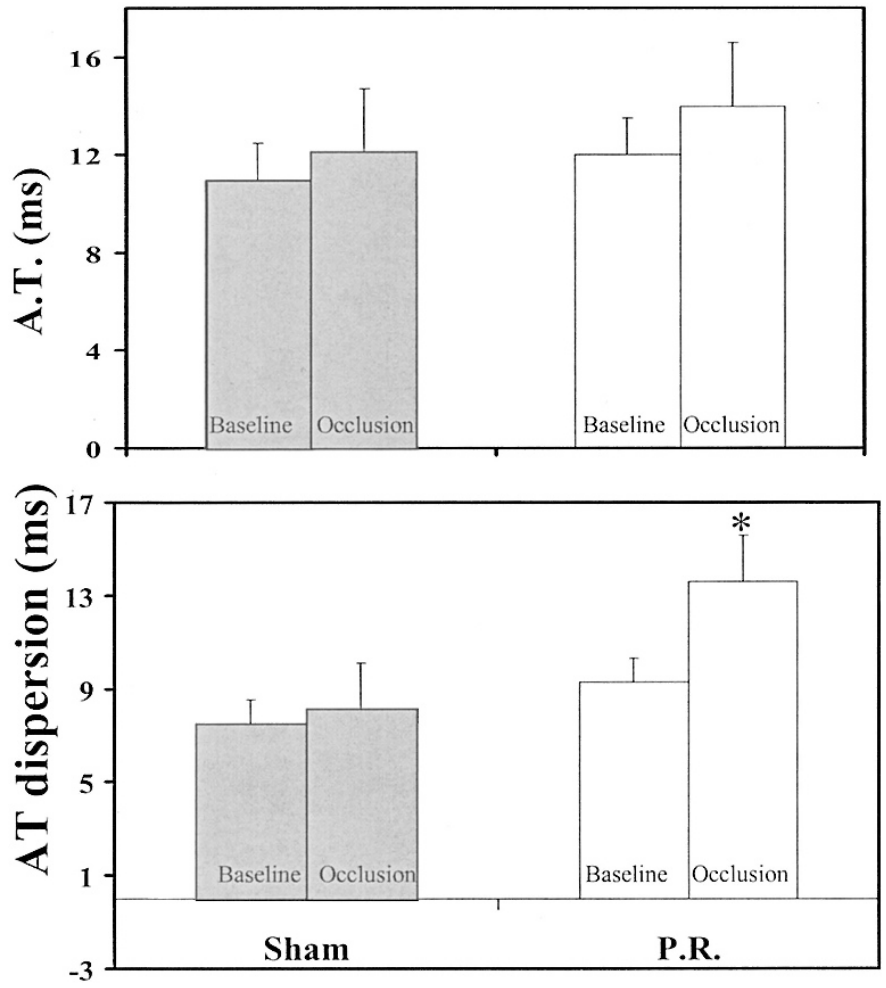

Figure 2. Changes in RV AT and the dispersion of RV activation during RV stretch. Although AT was unaltered by stretch, the dispersion of activation was increased in the PR group $(\square) .{ }^{*} p<0.05$ vs baseline.

from hearts with PR demonstrated a prolonged mechanical refractory period $\left(t_{\mathrm{o}}, 447 \pm 22 \mathrm{~ms}\right)$ compared with the SO hearts $(370 \pm 26 \mathrm{~ms} ; p<0.05)$ and a reduced $\tau(184 \pm 19$ versus $265 \pm 20 \mathrm{~ms} ; p=0.001$; Fig. 4).

APD, conduction velocity, and $\mathrm{R}_{\mathrm{i}} \cdot \mathrm{APD}_{95}$ was increased at all stimulation frequencies in the hearts with $\operatorname{PR}(p<0.01$; Fig.
A

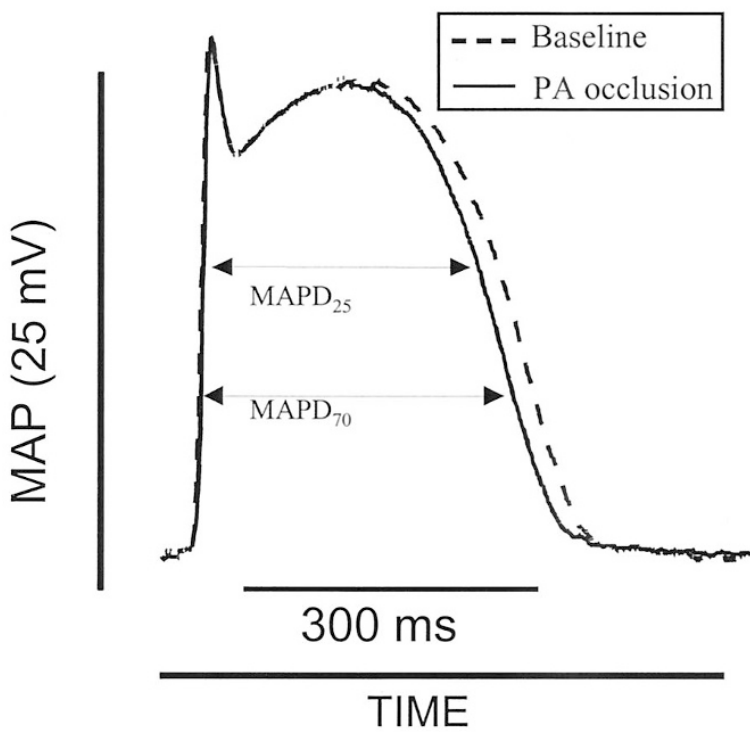

B
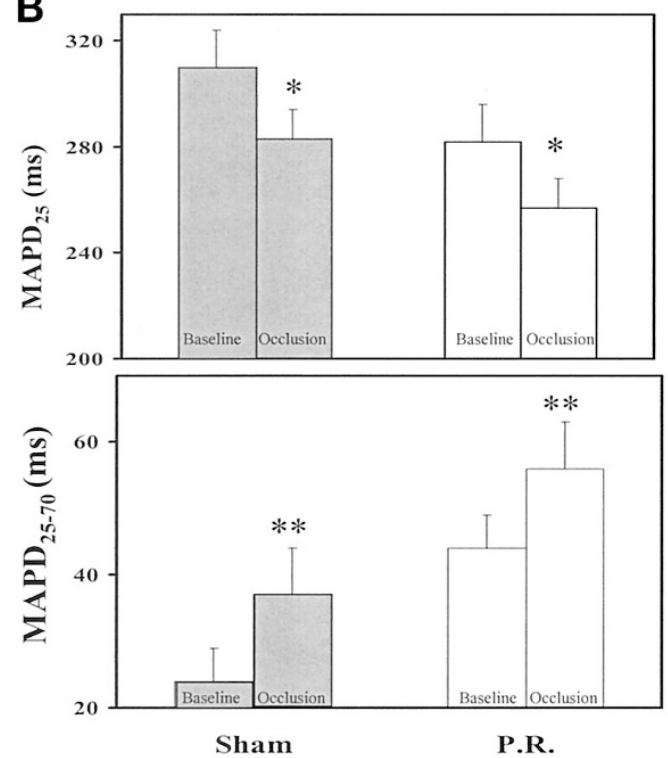

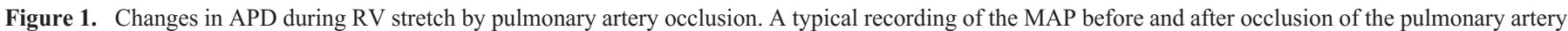

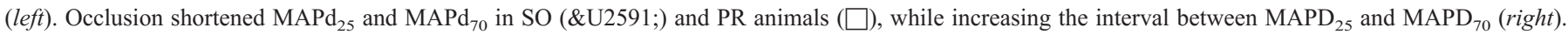
$* p<0.05 ; * * p<0.01$ vs baseline. 


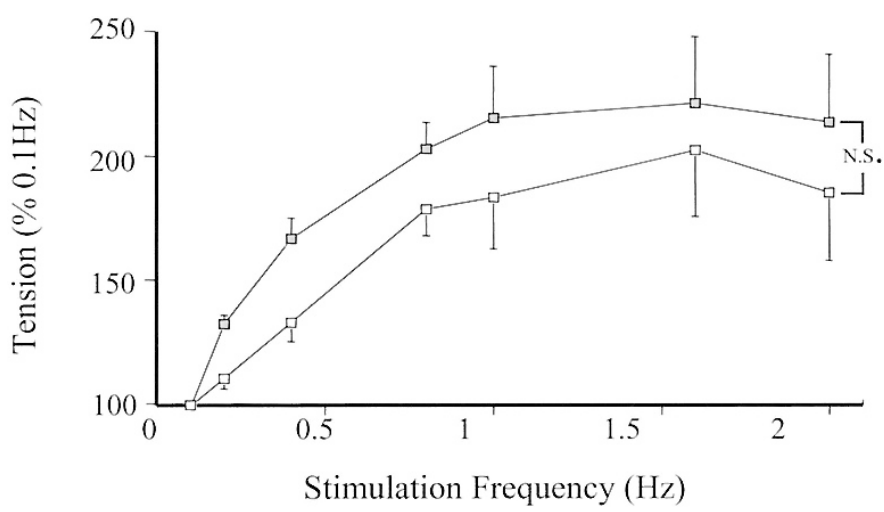

Figure 3. Force-frequency relationships in myocardium from PR and SO hearts. Steady state isometric tension is plotted as a function of frequency. All demonstrated a positive force-frequency relationship with no differences between myocardium from SO (\&U2591;) and PR ( $\square$ ) animals.

5). Conduction velocity was reduced in preparations from hearts with PR $(31.0 \pm 3.58$ versus $47.9 \pm 5.11 \mathrm{~cm} / \mathrm{s} ; p<$ $0.01)$. However, the time constant of upstroke of the AP $\left(\tau_{\text {ap }}\right)$ were similar in PR $(0.34 \pm 0.02 \mathrm{~ms})$ and SO hearts $(0.31 \pm$ $0.03 \mathrm{~ms}$ ), so that as a result, in hearts with PR, $R_{i}$ was increased by a factor of approximately $2.2(194 \pm 43$ versus $437 \pm 126$ $\Omega \cdot \mathrm{cm} ; p<0.025$; Fig. 6).

\section{DISCUSSION}

Late arrhythmic death is a significant problem in young adults after surgery for tetralogy of Fallot $(1,2)$. We have suggested $(3,4)$ that RV distension, secondary to chronic PR, provides the electrophysiologic milieu in which arrhythmias may develop. However, this is the first study to investigate the relationships between PR and the electrophysiologic properties of RV myocardium. Two main findings have arisen. First, after only 3 mo of PR the RV shows enhanced susceptibility to stretch-induced arrhythmias and increased inhomogeneity of activation. Second, myocardium from these ventricles show impaired mechanical restitution, increased intracellular resistivity, and a reduced conduction velocity.

$\mathrm{RV}$ weight tended to be greater in the PR animals, and the $\mathrm{RV}: \mathrm{LV}$ mass ratio was higher in this group. This phenomenon has also been observed in patients with chronic PR, in whom it is thought to reflect an adaptive mechanism for the maintenance of a low wall stress (19). Systolic myocardial performance as assessed from the force-frequency relationship was maintained in the PR group, an observation consistent with another study of chronic RV volume overload of up to $4 \mathrm{y}$ with tricuspid regurgitation (20). This is contrary to the rapid deterioration of $\mathrm{LV}$ function occurring after even short periods of LV volume overload (21), although the mechanisms for these differences between ventricles remain to be determined. Nonetheless, despite the preserved force-frequency response in the PR group, the presence of abnormal mechanical restitution indicates that more subtle abnormalities of function had developed. Mechanical restitution represents the change in the force of contraction with altered extrasystolic intervals and thus represents the negative inotropic effect of early myocardial activation (22). It may be a more sensitive measure of excita- tion-contraction coupling than steady state relationships between ventricular function and heart rate, as the time course of mechanical restitution closely follows that of availability of free calcium within the myocyte (23). Our observations of an increased refractory period and a shortened time constant for restitution are consistent with delayed recovery of the calciumrelease mechanisms of the sarcoplasmic reticulum in animals with PR, which might potentially be a precursor of overt impairment of systolic performance in the longer term.

There are divergent data on the changes in APD in hypertrophied ventricles. We observed that although, in vivo, MAP duration was similar in both groups, the measured APD was increased in the in vitro experiments. This apparent discrepancy may be explained by the fact that in vivo recordings were of epicardial MAPs whereas the in vitro measurements were made from endocardial myocytes. Indeed, a study of LV hypertrophy demonstrated that MAP duration in epicardial myocytes was unchanged whereas repolarization of endocardial and papillary muscle myocytes was prolonged (24). The mechanisms for the prolongation are not yet clear, as there is considerable variation in the response of membrane current systems to hypertrophic stimuli, which appears to depend on the nature of the stimulus and the species studied. Nonetheless, prolongation of AP duration per se will increase the likelihood of early after-depolarizations that may contribute to arrhythmia generation (25), a phenomenon that may be further augmented by the amplified transmural dispersion of repolarization (26).

One potential mechanism that might underlie MEF is through altered properties of stretch-activated channels (7). However, there is lack of consensus as to the contribution of these channels to arrhythmia in pathologic conditions associated with ventricular dilation. We used pulmonary arterial occlusion as a stimulus to assess the function of these channels in vivo. During PA occlusion the time to $\mathrm{MAPD}_{25}$ was abbreviated, suggesting a reduction in plateau duration of the AP, whereas the interval between $\mathrm{MAPD}_{25}$ and $\mathrm{MAPD}_{70}$ was prolonged, delaying phase 3 repolarization. These effects are consistent with activation of stretch-sensitive channels (27), which have a marked increase in opening probability in response to stretch, with a reversal potential of approximately $-30 \mathrm{mV}$. Activation would be expected to abbreviate the plateau phase of the AP and prolong phase 3 depolarization. Nonetheless, our observation that the responses to stretch were unaltered in PR animals suggests that although the tendency to exhibit stretch-induced arrhythmia was increased in the setting of PR, it is unlikely that this can be explained by an alteration per se in the properties of stretch-activated channels.

It is more likely that the increased activation dispersion in vivo and the reduced conduction velocity in vitro reflect the primary electrophysiologic changes associated with PR. Cable theory predicts that as cell diameter increases, conduction velocity will be increased. However, in this study conduction velocity was found to decrease. This reduction could result either from an attenuation of local circuit currents derived from inward currents driving the AP upstroke or an increase in the impedance of the intracellular pathway. The lack of change in the time constant of upstroke of the AP $\left(\tau_{\text {ap }}\right)$ indicated that the latter mechanism is responsible. Our calculation of $R_{i}$ by cable 
A

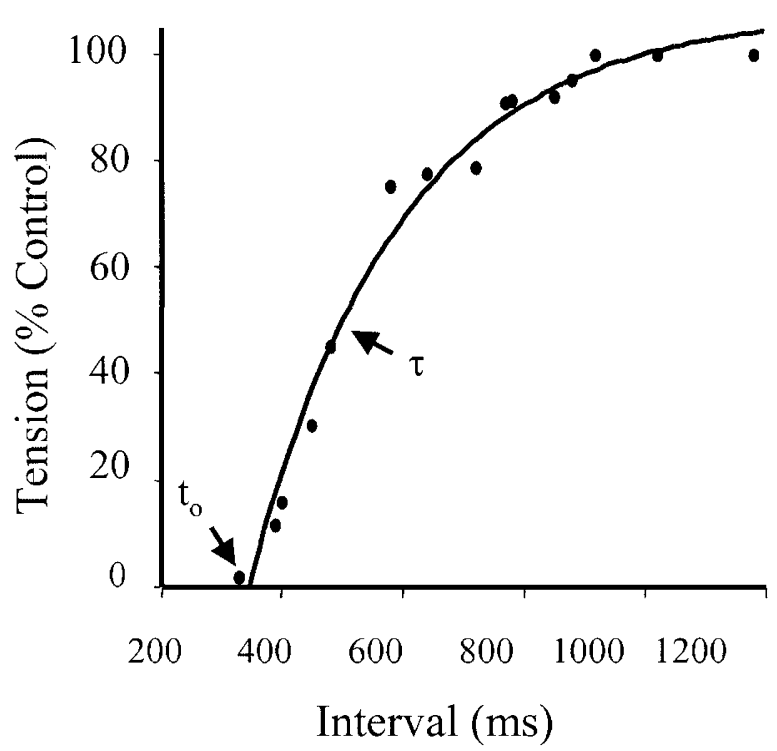

B

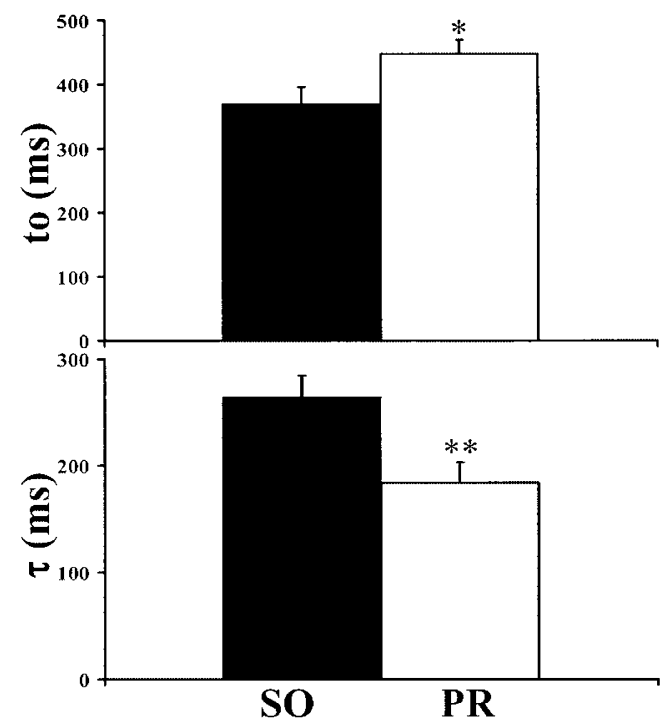

Figure 4. Mechanical restitution curve and group data for restitution characteristics. A curve from an SO animal, demonstrating a reduction in developed tension with shortening of extrasystolic interval (left) In the PR animals $t$ was reduced whereas $t_{0}$ was increased (right).

A

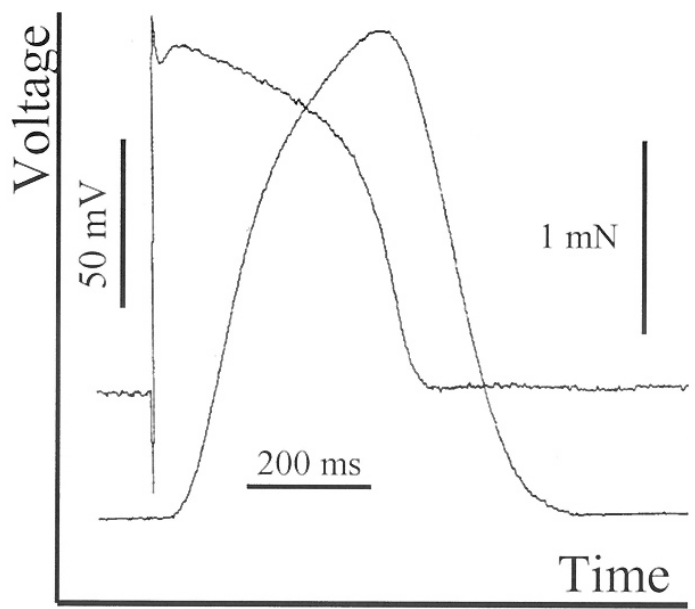

B

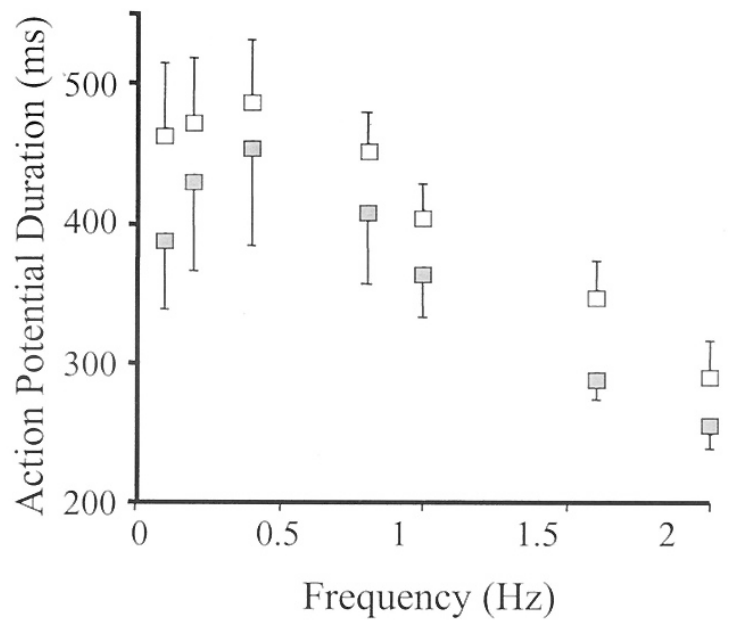

Figure 5. Recording of AP and tension (left) and group data for APD at changing stimulation frequency (right). At all stimulation frequencies APD was greater $(p<0.01)$ in PR $(\square)$ than in SO animals (圆).

analysis assumed that the cell diameter was similar in the two groups; if, as is likely (28 29), cell diameter was larger in the PR group, the proportional increase in $R_{i}$ would be even greater. Errors in the measurement of $\theta$ will disproportionately affect calculations of $R_{i}$, as $R_{i}$ is proportional to $\theta^{2}$. We estimated the experimental error in this measurement by examining the variability in repeated measurements of conduction delay within each specimen. This variability did not exceed $5 \%$. Thus the differences in $R_{i}$ between control and experimental groups could not have been explained by such errors.

The intracellular resistive pathway has at least two components; one caused by the resistivity of the sarcoplasm and the other caused by gap junctions between myocytes, mediated by connexins (30). It is more likely that changes in the latter explain our observations. Alteration of connexin electrical conduction can be mediated either by altering the number, distribution, and type of connexin subtypes or by decreasing the conductance of existing connexins, mediated for example by changes in intracellular $\mathrm{pH}$ or calcium, or by dephosphorylation. If connexin conductance were to decrease equally in all directions, then the increase in $R_{i}$ may preferentially attenuate transverse conduction and increase the propensity for reentrant circuits to develop (31); however, if redistribution were to occur, then the difference between longitudinal and transverse impedances would diminish. Changes in the expression of connexin isoforms were observed within $5 \mathrm{~d}$ of pressure overload of the RV owing to pulmonary artery banding in fetal sheep (32). Further studies will be required to investigate whether these changes also occur in PR. 

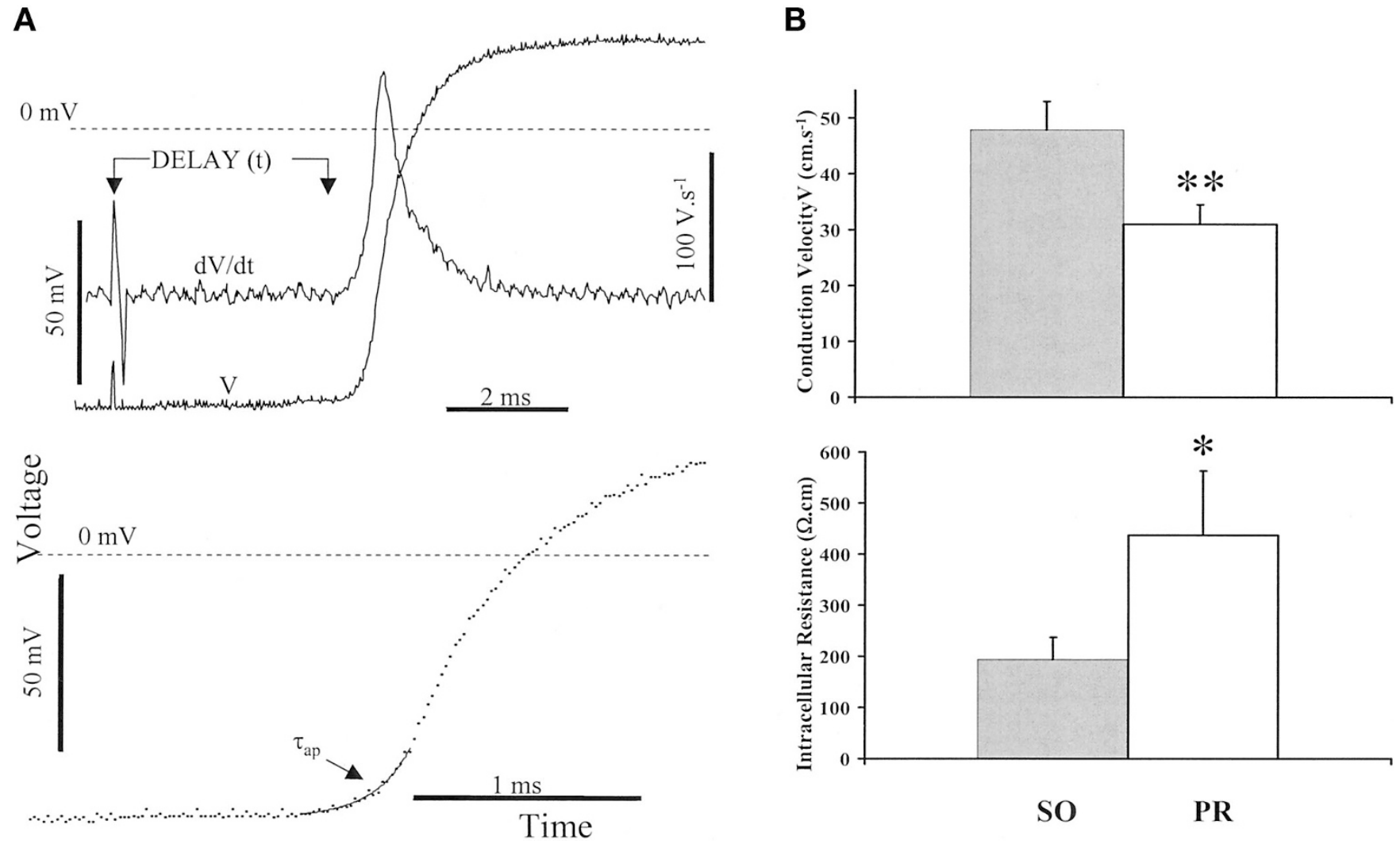

Figure 6. Changes in conduction velocity and intracellular resistance after chronic PR. Recording demonstrating the delay between the delivery of a stimulus and the upstroke of the AP at a known distance from the stimulation electrode, as well as the time constant for the AP upstroke (left). Conduction velocity was reduced in PR animals $(\square)$, and intracellular resistance was increased (right). ${ }^{*} p<0.05 ;{ }^{* *} p<0.01$, SO vs PR groups.

A number of factors have been suggested to contribute to arrhythmic death in patients after tetralogy repair. Recent data suggest postoperative PR makes an important contribution (3, 4). Here, we have shown that only 3 mo of PR increases the dispersion of activation, prolongs endocardial APD, and reduces conduction velocity. In addition, the slowed conduction velocity reflects an increase in intracellular resistivity, most likely related to altered gap junction properties. These findings provide the mechanistic basis for our clinical observation of an increase in QRS dispersion (33) and QRS duration (3) in patients after repair of tetralogy of Fallot, which is thought to accompany progressive ventricular dilation secondary to PR (3). The rate of this increase is one of the most sensitive markers for ventricular arrhythmia and sudden death (4). Our observations also help to delineate the contribution made by PR to arrhythmia. Although a previous animal model of chronic RV outflow tract obstruction and ventriculotomy (34) suggested that triggered mechanisms may be the predominant mechanism of tachycardia in patients after congenital heart surgery, the presence of frequent and complex automatic ventricular activity failed to predict clinically important ventricular arrhythmia or sudden death in at least two large clinical studies $(4,35)$. Our data emphasize the potential contribution of chronic PR to the development of reentry arrhythmia. There is evidence from electrophysiologic studies that ventricular tachycardia after repair of tetralogy of Fallot results from reentry mechanisms. Macro-reentry circuits have been demonstrated by signal averaging and catheter mapping (36). These studies have highlighted the contribution to these circuits of surgical scarring related to the ventriculotomy or to the ventricular septal patch, although reentry circuits have also been demonstrated at sites independent of visible scars (37). Our data suggest that isolated PR, unrelated to ventricular scarring, may predispose to reentry by altering the conduction velocity in the RV myocardium.

A potential limitation of our study relates to the assessment of RV performance in vivo. This assessment is widely recognized to be difficult, particularly because of the irregular shape of the RV cavity. Although no technique is ideal, we used the conductance catheter technique, which we consider to be an acceptable method to examine RV performance in the pressure-volume plane. A number of groups have provided validation of this method, demonstrating, for example, a close relationship between changes in RV volume measured with the conductance catheter and stroke volume measured with a flow probe on the pulmonary artery (38). We have demonstrated that despite the complex shape of the RV, the conductance technique provides an accurate measure of the volume of $\mathrm{RV}$ casts (39), and others have suggested that RV volume estimated in vivo using the conductance technique is unaffected by shape (40).

\section{CONCLUSIONS}

In conclusion, experimentally induced PR changes the electromechanical properties of the myocardium, which could 
explain some of the electrophysiologic abnormalities after repair of tetralogy of Fallot. These changes would be expected to enhance the establishment of reentrant circuits in the myocardium and predispose to ventricular arrhythmia.

\section{REFERENCES}

1. Silka MJ, Hardy BG, Menashe VD, Morris CD 1998 A population-based prospective evaluation of risk of sudden cardiac death after operation for common congenital heart defects. J Am Coll Cardiol 32:245-251

2. Garson Jr A, Randall DC, Gillette PC, Smith RT, Moak JP, McVey P, McNamara DG 1985 Prevention of sudden death after repair of tetralogy of Fallot: treatment of ventricular arrhythmias. J Am Coll Cardiol 6:221-227

3. Gatzoulis MA, Till JA, Somerville J, Redington AN 1995 Mechanoelectrical interaction in tetralogy of Fallot: QRS prolongation relates to right ventricular size and predicts malignant ventricular arrhythmias and sudden death. Circulation 92:231-237

4. Gatzoulis MA, Balaji S, Webber SA, Siu SC, Hokanson JS, Poile C, Rosenthal M, Nakazawa JH, Gillette PC, Webb GD, Redington AN 2000 Risk factors for arrhythmia and sudden cardiac death late after repair of tetralogy of Fallot: a multicentre study. Lancet 356:975-981

5. Kori Y, Suwa K, Shiroma K 1989 Ventricular premature contraction after repair of tetralogy of Fallot - the influence of postoperative factors, particularly the right ventricular regional wall motion. Jpn Circ J 53:213-218

6. Lab MJ, Taggart P, Sachs F 1996 Mechano-electrical feedback. Cardiovasc Res $32: 1-2$

7. Lab MJ 1996 Mechanoelectric feedback (transduction) in heart: concepts and implications. Cardiovasc Res 32:3-14

8. Levine RA, Gibson TC, Aretz T, Gillam LD, Guyer DE, King ME, Weyman AE 1984 Echocardiographic measurement of right ventricular volume. Circulation 69:497-505

9. Redington AN 1998 Right ventricular function. In: Redington AN, Brawn WJ, Deanfield JE, Anderson RH (eds) The Right Heart in Congenital Heart Disease. Oxford University Press, Oxford, pp 17-24

10. Weber KT, Janicki JS, Shroff S, Fishman AP 1981 Contractile mechanics and interaction of the right and left ventricles. Am J Cardiol 47:686-695

11. Redington AN, Rigby ML, Shinebourne EA, Oldershaw PJ 1990 Changes in the pressure-volume relation of the right ventricle when its loading conditions are modified. Br Heart J 63:45-49

12. Franz MR 1996 Mechano-electrical feedback in ventricular myocardium. Cardiovase Res 32:15-24

13. Chaturvedi RR, Lincoln C, Gothard JW, Scallan MH, White PA, Redington AN, Shore DF 1998 Left ventricular dysfunction after open repair of simple congenita heart defects in infants and children: quantitation with the use of a conductance catheter immediately after bypass. J Thorac Cardiovasc Surg 115:77-83

14. Derrick GP, Narang I, White PA, Kelleher A, Bush A, Penny DJ, Redington AN 2000 Failure of stroke volume augmentation during exercise and dobutamine stress is unrelated to load-independent indexes of right ventricular performance after the Mustard operation. Circulation 102(19 Suppl 3):III-154-III-159

15. Chaturvedi RR, Kilner PJ, White PA, Bishop A, Szwarc R, Redington AN 1997 Increased airway pressure and simulated branch pulmonary artery stenosis increase pulmonary regurgitation after repair of tetralogy of Fallot: real-time analysis with a conductance catheter technique. Circulation 95:643-649

16. Walker MJA, Curtis MJ, Hearse DJ, Campbell RW, Janse MJ, Yellon DM, Cobbe SM, Coker SJ, Harness JB, Harron DW, Higgins AJ, Julian DG, Lab MJ, Manning AS, Northover BJ, Parratt JR, Riemersma RA, Riva E, Russell DC, Sheridan DJ, Winslow E, Woodward B 1988 The Lambeth Conventions: guidelines for the study of arrhythmias in ischaemia infarction, and reperfusion. Cardiovasc Res 22:447-455

17. Tasaki I, Hagiwara S 1957 The capacity of the muscle fibre membrane. Am J Physio 188:423-429

18. Cooklin M, Wallis RJ, Sheridan DJ, Fry CH 1997 Changes in cell-to-cell electrical coupling associated with left ventricular hypertrophy. Circ Res 80:765-771
19. Davlouros PA, Kilner PJ, Hornung TS, Li W, Francis JM, Moon JC, Smith GC, Tat T, Pennell DJ, Gatzoulis MA 2002 Right ventricular function in adults with repaired tetralogy of Fallot assessed with cardiovascular magnetic resonance imaging: detrimental role of right ventricular outflow aneurysms or akinesia and adverse right-toleft ventricular interaction. J Am Coll Cardiol 40:2044-2052

20. Ishibashi Y, Rembert JC, Carabello BA, Nemoto S, Hamawaki M, Zile MR, Greenfield JC, Cooper G 2001 Normal myocardial function in severe right ventricular volume overload hypertrophy. Am J Physiol 280:H11-H16

21. Urabe Y, Mann DL, Kent RL, Nakano K, Tomanek RJ, Carabello BA, Cooper G 1992 Cellular and ventricular contractile dysfunction in experimental canine mitral regurgitation. Circ Res 70:131-147

22. Neumann T, Ravens U, Heusch G 1998 Characterization of excitation-contraction coupling in conscious dogs with pacing induced heart failure. Cardiovasc Res $37: 456-466$

23. Cooper IC, Fry CH 1990 Mechanical restitution in isolated mammalian myocardium: species differences and underlying mechanisms. J Mol Cell Cardiol 22:439-452

24. Keung EC, Aronson RS 1981 Non-uniform electrophysiological properties and electrotonic interaction in hypertrophied rat myocardium. Circ Res 49:150-158

25. Aronson RS 1981 Afterpotentials and triggered activity in hypertrophied myocardium from rats with renal hypertension. Circ Res 48:720-727

26. Yan GX, Rials SJ, Wu Y, Liu T, Xu X, Marinchak RA, Kowey PR 2001 Ventricular hypertrophy amplifies transmural repolarization dispersion and induces early afterdepolarization. Am J Physiol Heart Circ Physiol 281:H1968-H1975

27. Craelius W, Chen V, el-Sherif N 1988 Stretch activated ion channels in ventricular myocytes. Biosci Rep 8:407-414

28. Marino TA, Kent RL, Uboh CE, Fernandez E, Thompson EW, Cooper G 1985 Structural analysis of pressure versus volume overload hypertrophy of cat right ventricle. Am J Physiol 249:H371-H379

29. Kato S, Koide M, Cooper G, Zile MR 1996 Effects of pressure- or volume-overload hypertrophy on passive stiffness in isolate adult cardiac muscle cells. Am J Physiol 271:H2575-H2583

30. Saffitz JE, Yamada KA 1999 Gap junction distribution in the heart. In: Zipes DP, Jalife J (eds). Cardiac Electrophysiology: From Cell to Bedside, 3rd Ed. WB Saunders, Philadelphia, pp 179-187

31. Spach MS, Josephson M 1994 Initiating reentry: the role of non-uniform anisotrophy in small circuits. Electrophysiology 5:182-209

32. Montgomery MO, Jiao Y, Phillips SJ, Singh G, Xu J, Basara R, Litvin J 1998 Alterations in sheep fetal right ventricular tissue with induced hemodynamic pressure overload. Basic Res Cardiol 93:192-200

33. Gatzoulis MA, Till JA, Redington AN 1997 Depolarization-repolarization inhomogeneity after repair of tetralogy of Fallot: the substrate for malignant ventricular tachycardia? Circulation 95:401-404

34. Garson Jr A 1984 Ventricular dysrhythmias after congenital heart surgery: a canine model. Pediatr Res 18:1112-1120

35. Cullen S, Celermajer DS, Franklin RC Hallidie-Smith KA, Deanfield JE 1994 Prognostic significance of ventricular arrhythmia after repair of tetralogy of Fallot: a 12-year prospective study. J Am Coll Cardiol 23:1151-11555

36. Biblo LA, Carlson MD 1994 Transcatheter radiofrequency ablation of ventricular tachycardiac following surgical correction of tetralogy of Fallot. Pacing Clin Electrophysiol 17:1556-1560

37. Stevenson WG, Delacretaz E, Friedman PL, Ellison KE 1998 Identification and ablation of macroreentrant ventricular tachycardia with the CARTO electroanatomical mapping system. Pacing Clin Electrophysiol 21:1448-1456

38. Dickstein ML, Yano O, Spotnitz HM, Burkhoff D 1995 Assessment of right ventricular contractile state with the conductance catheter technique in the pig. Cardiovasc Res 29:820-826

39. White PA, Bishop AJ, Conroy B, Oldershaw PJ, Redington AN 1995 The determination of volume of right ventricular casts using a conductance catheter. Eur Heart J $16: 1425-1429$

40. Woodard JC, Bertram CD, Gow BS 1987 Right ventricular volumetry by catheter measurement of conductance. Pacing Clin Electrophysiol 10:862-867 